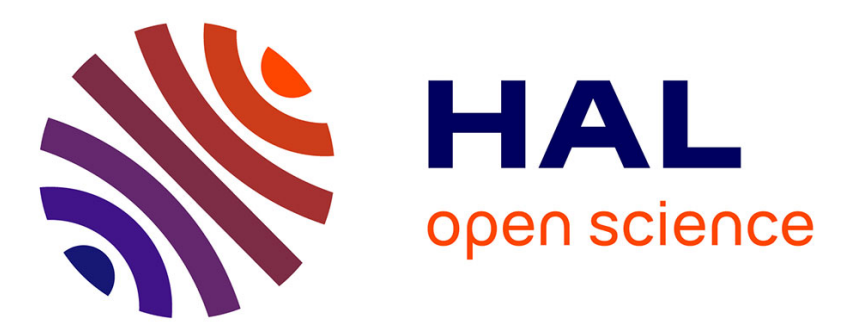

\title{
Selecting Theories in an Ontology-Based ITS Authoring Environment
}

Jacqueline Bourdeau, Riichiro Mizoguchi, Valéry Psyché, Roger Nkambou

\section{To cite this version:}

Jacqueline Bourdeau, Riichiro Mizoguchi, Valéry Psyché, Roger Nkambou. Selecting Theories in an Ontology-Based ITS Authoring Environment. 7th International Conference (ITS 2004), 2004, Maceió, Brazil. pp.150-161. hal-00190672

\section{HAL Id: hal-00190672 \\ https://telearn.archives-ouvertes.fr/hal-00190672}

Submitted on 23 Nov 2007

HAL is a multi-disciplinary open access archive for the deposit and dissemination of scientific research documents, whether they are published or not. The documents may come from teaching and research institutions in France or abroad, or from public or private research centers.
L'archive ouverte pluridisciplinaire HAL, est destinée au dépôt et à la diffusion de documents scientifiques de niveau recherche, publiés ou non, émanant des établissements d'enseignement et de recherche français ou étrangers, des laboratoires publics ou privés. 


\title{
Selecting Theories in an Ontology-Based ITS Authoring Environment
}

\author{
Jacqueline BOURDEAU*, Riichiro MIZOGUCHI**, Valéry PSYCHÉ* \& Roger \\ NKAMBOU*** \\ *Centre de recherche LICEF, Télé-université \\ 4750 Henri-Julien, Montréal (Québec) H2T 3E4, Canada ; Tel: 514-840-2747 \\ Email : bourdeau@licef.teluq.uquebec.ca,vpsyche@licef.teluq.uquebec.ca, \\ ** ISIR, Osaka University, 8-1 Mihogaoka, Ibaraki, Osaka, 567-0047 Japan, \\ Email:miz@ei.sanken.osaka-u.ac.jp \\ *** Département d'informatique, Université du Québec à Montréal \\ Case postale 8888, succursale Centre-ville, Montréal (Québec) Canada - H3C 3P8 \\ Email :nkambou.roger@uqam.ca
}

\begin{abstract}
This paper introduces the rationale for concrete situations in the authoring process that can exploit a theory-aware Authoring Environment. It illustrates how Ontological Engineering (OE) can be instrumental in representing the declarative knowledge needed, and how an added value in terms of intelligence can be expected for both authoring and for learning environments.
\end{abstract}

Keywords: Ontologies; Ontological Engineering; Intelligent Tutoring Systems; Authoring Environments; Instructional Theories 


\title{
Selecting Theories in an Ontology-Based ITS Authoring Environment
}

\author{
Jacqueline BOURDEAU*, Riichiro MIZOGUCHI**, Valéry PSYCHÉ**** \& Roger \\ NKAMBOU*** \\ *Centre de recherche LICEF, Télé-université \\ 4750 Henri-Julien, Montréal (Québec) H2T 3E4, Canada ; Tel: 514-840-2747 \\ Email : bourdeau@licef.teluq.uquebec.ca,vpsyche@licef.teluq.uquebec.ca, \\ ** ISIR, Osaka University, 8-1 Mihogaoka, Ibaraki, Osaka, 567-0047 Japan, \\ Email:miz@ei.sanken.osaka-u.ac.jp \\ *** Département d'informatique, Université du Québec à Montréal \\ Case postale 8888, succursale Centre-ville, Montréal (Québec) Canada - H3C 3P8 \\ Email : nkambou.roger@uqam.ca
}

\begin{abstract}
This paper introduces the rationale for concrete situations in the authoring process that can exploit a theory-aware Authoring Environment. It illustrates how Ontological Engineering (OE) can be instrumental in representing the declarative knowledge needed, and how an added value in terms of intelligence can be expected for both authoring and for learning environments.
\end{abstract}

\section{Introduction}

Ontological Engineering may prove to be instrumental in solving several problems known in the field of Artificial Intelligence and Education (AIED) [1]. Preliminary work shows that significant results can be obtained in terms of knowledge systematization and of instructional planning [2];[3];[4]. Results obtained in other fields [5], [6], [7] indicate significant added value and justify efforts to further explore this direction. In a previous paper [8], we envisioned the power of ontologies to sustain the ITS authoring process in an ITS Authoring Environment, and explored methodologies for engineering declarative knowledge from instructional and learning sciences. This paper introduces the rationale for concrete situations in the authoring process that exploits a theory-aware Authoring Environment. It illustrates how Ontological Engineering can be instrumental in representing the declarative knowledge needed, and how an added value in terms of intelligence can be expected for Intelligent Tutoring Systems (ITS) authoring environments.

\section{Value of Ontologies for ITS and for the Authoring Process}

\subsection{Why should a theory-aware environment be beneficial to the authoring of ITS?}

Existing ITS authoring environments aim at combining authoring tools and knowledge representation [9], but so far no ITS authoring environment possesses the desired functionalities of an intelligent authoring system such as Retrieve appropriate theories for selecting instructional strategies or Provide principles for structuring a learning environment. Declarative knowledge is mainly absent in those systems, as is the maintenance of knowledge base's integrity. Ontological Engineering can solve these problems by proposing a declarative knowledge modeling approach. The semantic-based knowledge systematization that would result from this approach could provide a gateway to learning objects and their management. Ontologies are considered a solution to the problems of indexing, 
assembling and aggregating Learning Objects in a coherent way [10], [11], [12], either automatically, semi-automatically or done by humans.

Viewing the authoring task as part of instructional design (in which design decisions are made) access to theoretical knowledge should improve quality and consistency of the design. From the ontological point of view, it is possible to suggest common concepts and a conceptual structure to explain existing theories in a harmonized way. Our effort to systematize theoretical knowledge and to integrate it into a design methodology for authoring tasks is described in [1]. We have developed a minimal ontology for illustrating how our ideas can help an author or an agent to build a learning scenario by reflecting on possible variations based on instructional theories. A long term perspective for this work is to provide the next generation of authoring systems with a scientific basis for semantic standards of learning objects and their management.

\subsection{What is the full power of an ontology-based system when adequately deployed?}

Exploring the power of ontologies for ITS and for the authoring process raises the following question: what is the full power of an ontology-based system when adequately deployed? A successful experiment was conducted by Mizoguchi [6] in deploying ontology-based knowledge systematization of functional knowledge into a production division of a large company. Although the domain is different from educational knowledge, we believe that it is applicable to the knowledge systematization of learning and instructional sciences. One of the key claims of our knowledge systematization is that the concept of function should be defined independently of an object that can possess it and of its realization method. This in effect releases the function for re-use in multiple domains.

Consider: If functions are defined depending on objects and their realization, few functions are reused in different domains. In the systematization reported in Mizoguchi, a six-layer ontology and knowledge base was built using functional knowledge representation frameworks to capture, store and share functional knowledge among engineers and enable them to reuse that functional knowledge in their daily work life with the help of a functional knowledge server. It was successfully deployed inside the Production Systems Division of Sumitomo Electric Industry, Ltd., with the following results: 1) the same document can be used for redesign, design review, patent writing and troubleshooting; 2) Patent writing process is reduced by one third; 3) design review goes extremely better than before, 4) troubleshooting is much easier than before, 5) it enables collaborative work among several kinds of engineers. It demonstrates that operational knowledge systems based on developed ontologies can work effectively in a real world situation.

What is the similarity of situations in the manufacturing and the educational domains? Both have rich concepts and experiential knowledge. However, neither a common conceptual infrastructure nor shareable knowledge bases are available in those domains. Rather, each is characterized by multiple viewpoints and a variety of concepts. The success reported in [6] leads us to believe that similar results can be obtained in the field of ITS, and that efforts should be made towards achieving this goal of building ITS frameworks capable of sharing educational knowledge..

\section{Intelligence in ITS Authoring and Learning Environments}

\subsection{Value of Ontology for ITS Learning Environments}

The power of the intelligent behaviour of an ITS Learning Environment relies on the knowledge stored in it. This knowledge deals with domain expertise, pedagogy, interaction and tutoring strategy. Each of those dimensions is usually implemented as an agent-based system. A simplified view of an ITS is that of a multi-agent system in which domain expert, pedagogical and tutoring agents cooperate to deliver an optimal learning environment with respect to the learning goals. In order to achieve this, ITS agents need to share common interpretations during their interactions. How does ontology engineering contribute to this?

Several views or theories of domain knowledge taxonomy can be found in the literature as well as discussions of how this knowledge can be represented in a knowledge-based system for learning/teaching purposes. For instance, Gagné et al. suggested five categories of knowledge that are responsible for most human activity; some of these categories include several types of knowledge. Merrill suggested a different view of possible learning outcomes or domain knowledge. Even if 
there are some intersections between existing taxonomies, it is very difficult to implement a system that can integrate these different views without a prior agreement on the semantics of what the student should learn.

We believe that ontological engineering can help the domain expert agent to deal with these different views in two ways: 1) by defining "things" associated with each taxonomy and their semantics, the domain knowledge expert can then inform other agents of the system in the course of their interaction. 2) by creating an ontology for a meta-taxonomy which can include different views. We are experimenting with each of these approaches.

Ontological engineering can also be instrumental for including different instructional theories into the same pedagogical agent: for example Gagné's learning events theory, or Merrill component-based theory. This could lead to the development of multi-instructional theories-based ITS which could exploit principles from one instructional theory or another with respect to the current instructional goal.

Furthermore, ontology engineering is essential for the development of ITSs in which several agents (tutor, instructional planner, expert, profiler) need to agree about the definition and the semantics of the things they share during a learning session. Even if pure multi-agent platforms based on standards such as FIPA offer ontology-free ACL (Agent Communication Language), ontological engineering is still necessary because the ontology defines shared concepts, which are in turn sent to the other party during the communication. It is possible to implement using FIPA-ACL standards in which "performatives" (communication acts between agents) can take a given ontology as a parameter to make it possible for the other party to understand and to interpret concepts or things included in the content of the message.

By adding intelligence to ITS authoring environments in the form of theory-aware environments, we could also provide not only curriculum knowledge, not only instructional strategies, but also the foundations, the rationale upon which the tutoring system relies and acts. As a result of having ontology-based ITS authoring environments, we can ensure that: 1) the ITS generated can be more coherent, well-founded, scrutable, and expandable; 2) the ITS can explain and justify to learners the rationale behind an instructional strategy (based on learning theories), and therefore support metacognition; 3) the ITS can even offer some choice to learners in terms of instructional strategies, with pros and cons for each option, thus supporting the development of autonomy and responsibility.

Having access to multiple theories (instead of one) in an ITS authoring environment such as CREAM-tools [13] would offer added value through: 1) the possible diversity offered to authors and learners, through the integration of multiple theories into a common knowledge base, 2) a curriculum planning module that would then be challenged to select among theories, and would therefore have to be more intelligent, and 3) an opportunity for collaboration between authors (even with different views of instructional or learning theory) in the development of ITS modules.

\subsection{What benefits would the general functionalities of a theory-aware ITS Authoring Environment offer?}

In an Ontology-based Authoring Environment, authors (human or software) could benefit from accessing theories to: 1) make design decisions (macro, micro) after reflection and reasoning, 2) communicate about or explain their design decisions , 3) check consistency among design decisions, intra-theory and inter-theories, 4) produce scrutable learning environments, 5) use heuristical knowledge grounded in theoretical knowledge.

Useful functionalities could include such queries as: 1) asking the system what theories apply best to this or that learning situation/goal, 2) asking the system to show examples, 3) asking the system for advice on whether this element of a theory can be combined to an element from another theory, the risk in doing so, other preferable solutions, etc.

Among the variations depending on theories in design or authoring decisions, some can be called paradigmatic, since they refer to a fundamental view of learning or of instruction [8]: instructivist, constructivist, or socioconstructivist. Other variations refer to educational strategies, some are specific to the characteristics of learners or to the subject matter. The following section describes a decision to be made by authors among variations from theories, and illustrates how an ontology can support this decision-making process.

Currently Such functionalities are not available in existing ITS authoring environments, as stated by Murray in his review of existing ITS authoring environments [9]. When these environments include theoretical knowledge, it is hard-wired and procedurally implemented in the system so that it cannot be 
flexible enough to satisfy users' goal. Moreover, these environments cannot know if the hard-wired theory is appropriate or not for the user's goal, they merely impose it on the authors. In Murray's classification, pedagogy-oriented systems rely upon instructional or teaching strategies for curriculum planning, but they do not take into account commonalities nor variations among theories. This limitation can be overcome by having theory-aware systems with multi-instructional theories, exploited by authors or agents.

\section{Selecting an instructional strategy}

In the course of designing instruction or authoring a learning environment, decisions are made as to what will be provided to learners in order to support, to foster or to assess their learning. Such decisions may either rely on well-thought-out, explicit reasons, or simply be intuitive, or ad hoc, or based on personal experience. In order to obtain science-based ITS design, these decisions need to be based on theories. Since ontologies are an effective form of declarative knowledge representation, and if ontological engineering is a methodology to develop this knowledge representation, a theory-aware authoring environment could effectively serve the decisions to be made for selecting an instructional strategy. This section will introduce the decision-making process for selecting an instructional strategy, and the variations based on respective theories. An implementation of a theory-aware environment to support these decisions will be described, as it illustrates the design process of a lesson in the field of Optics.

\subsection{The case of selecting an instructional strategy in the authoring process}

When designing instruction or authoring a learning environment, two types of decisions are to be made: macro-decisions for strategies, and micro-decisions for designing the learning material or the organization of learning activities. Decisions about instructional strategies are the most strategic and govern the decisions about learning material and organization. These decisions are based on: 1) theories that are accepted and respected by authors, 2) results of the analysis conducted before the design, such as analysis of content, context, expectations, etc. Such decisions are made by a person or a team acting as designers if the authoring process is done by humans; Otherwise, the choices are made by a system if the ITS authoring environment has a curriculum planning component; by an instructor or even a learner if provided with this freedom to choose.

The impact of such decisions is the following: selecting an instructional strategy should 'govern' or 'orient' or 'inspire' the development of the learning environment and organization and therefore influence the learning process. A good decision is a strategy that is coherent with the theory, which is the most adequate one as it relates to the goals and the conditions of learning, and respects the philosophy of the persons or organizations. In terms of granularity, this decision applies to the level of the 'learning unit', with objectives, learning activities and assessment. A decision remains good as long as it proves to have coherence and potential effectiveness. In some situations, designers have good reasons to combine elements from various theories into one scenario. If theoretical knowledge is specified and structured in an ontology, it allows for such combinations under constraint checking, thus reducing the risk of errors.

\subsection{Variations around three theories to design a lesson in Optics}

Dependence between instructional theory and strategy is best illustrated in the book edited by Reigeluth: 'Instructional Theories in Action: Lessons Illustrating Selected Theories and Models [14]. Reigeluth asked several authors to design a lesson based on a specific theory, having in common the subject matter, the objectives, and the test items. The objectives included both concept learning and skill development. The lesson is an introduction to the concepts of lens, focus and magnitude in optics. The book offers eight variations of the lesson, each one being an implementation of eight existing and recognized theories. Reigeluth gives as warnings to this exercise that: 1) despite the fact that each theory uses its own terminology, they have much in common, 2) each theory has its limitations, and none of them covers the full complexity of the design problem, none of them takes into account the large number of variables that play a role, 3) the main variation factor is how much the strategy is appropriate to the situation, 4) authors would benefit to know and have access to all existing ones. In 
the same book, Schnellbecker, in his effort to compare and contrast the different approaches, underlines that there is no such thing as a 'truth character' in the selection of a model. Variations among the lessons are of two kinds: intra-theory and inter-theory. Each implementation of one theory is specific, and could give room to a range of other strategies, all of them referring to the same principles. Intertheory variations represent fundamental differences in how one views learning and instruction, in terms of paradigm.

Since we are mainly interested in the examination of variations among theories, we concentrated on inter-theories variations. We selected three theories: Gagné-Briggs, Merrill, and Collins, and we selected one objective of concept learning (skill development is to be examined under a different study). The Gagné-Briggs theory of instruction was the first one to directly and explicitly rely on a learning theory. It is comprehensive of cognitive, affective and psycho-motor knowledge; the goal of learning is performance, and the goal of instruction is effectiveness. Merrill's Component Display theory shares the same paradigm as Gagné-Briggs', but suggests a different classification of objectives, and provides more detailed guidelines for learning organization and learning material. The lesson drawn by Collins refers to principles extracted from good practices and to scientific inquiry as a metaphor to learning; its goals are oriented towards critical thinking rather than performance.

\subsection{Ontological engineering methodology and results}

This section documents the methodology used for building the ontology and the models, and presents the results. The view of an ontology and of ontological engineering is the one developed and applied at Mizlab [15]. From the three steps proposed by Mizoguchi [15], the first one, called Level 1, has been developed, and consists of term extraction and definition, hierarchy building, relation setting, and model building. A Use Case was built to obtain the ontological commitments needed [17], and competency questions were sketched as suggested by Gruninger and Fox [16]. Concept extraction was performed based on the assumptions expressed by Noy and McGuiness [18]. The definition of a 'role' refers to Kozaki [19].

The Ontology environment used for the development of the ontology is Hozo [19], an environment composed of a graphic interface, an ontology editor and an ontology and models server in a client-server architecture.

Use-case. The definition of the domain of instruction has been done based on the ideas developed in [8]. A set of competency questions [16] was also sketched, as well as preliminary queries that our authoring environment prototype should be able to answer, such as: What is the most appropriate instructional theory? Which kind of learning activity or material do we need based on instructional theory chosen? At this stage we made ontological commitments [17] to which domain we wanted to model, how we wanted to do it, under which goals, in which order, and in which environment. The use case was done from the point of view of an author (human or software) having to select an instructional strategy to design a lesson. The lesson selection is usually done based on the learning conditions that have been previously identified. The result generated by the authoring environment is an instructional scenario based on the instructional strategy which best satisfies the learning conditions. Building the Use Cases was done by analyzing the expectations for theory-aware authoring, and by analyzing commonalities and variations among the three lessons. Figure 1 shows the result of this analysis in the form of a synoptic table. This use case illustrates an instructional scenario for teaching a concept in optics to secondary school learners, based on the three theories. 


\begin{tabular}{|c|c|}
\hline \multicolumn{2}{|c|}{$\begin{array}{l}\text { Use Case of Instructional Scenario Based on Objective : Student will be able to define focal length } \\
\text { Learning Content : Focal length }\end{array}$} \\
\hline 1. Instructional Theory & Gagné-Briggs' theory of Instruction \\
\hline 1.1. Prerequisite & Identify Focal Point \\
\hline 1.2. Teaching Strategy & Expository \\
\hline 1.3. Teaching Material & Workbook with visual representation \\
\hline 1.4. Assessment & Quiz \\
\hline 1.5. Activity type & $\begin{array}{l}\text { 1) Informing the learner of the lesson objective, 2) Presenting the stimulus } \\
\text { material with distinctive features, 3) Providing learning guidance, 4) Eliciting } \\
\text { performance, 5) Providing informative feedback, 6) Assessing Performance }\end{array}$ \\
\hline 2. Instructional Theory & Component display theory by M.D. Merrill \\
\hline 2.1. Prerequisite & Remember - Instance - Fact, Use - Concept \\
\hline 2.2. Learning Content & Focal Length \\
\hline 2.3. Teaching Strategy & Expository and Practice \\
\hline 2.4. Teaching Material & Printed Study Sheet \\
\hline 2.5. Assessment & Fill in the blank test \\
\hline 2.6. Activity type & $\begin{array}{l}\text { 1) Introduction, 2) Reference Example, 3) Definition, 4) Learning Tip, 5) } \\
\text { Practice, 6) Study Problems, 7) Feedback }\end{array}$ \\
\hline 3. Instructional Theory & Theory of Inquiry Teaching by A. Collins \\
\hline 3.1. Prerequisite & Terminology about lens \\
\hline 3.2. Learning Content & Focal Length \\
\hline 3.3. Teaching Strategy & Inquiry Dialogue \\
\hline 3.4. Teaching Material & Lenses, magnifying glass, lenses \\
\hline 3.5. Assessment type & Question test \\
\hline 3.6. Activitiy type & $\begin{array}{l}\text { 1) Preliminary, 2) Forming hypothesis, 3) Testing hypothesis, 4) Entrapping } \\
\text { Students, 5) Varying cases systematically, 6) Questioning authority, 7) Testing } \\
\text { hypothesis }\end{array}$ \\
\hline
\end{tabular}

Table 1. Use Case of Instructional Scenario

According to these uses cases, the author is informed of: the necessary prerequisites to reach the lesson objective, the learning content, the teaching strategy, the teaching material, the assessment, the activities order and type. The activities proposed are based on Gagné's instructional events, Merrill's performance/content matrix and Collins's instructional techniques.

Term extraction and definition. This operation was conducted based on the assumptions [18] that; 1) there is no one correct way to model a domain, 2) ontology development is necessarly an iterative process, 3) concepts in the ontology should be close to objects (physical or logical) and relationships in your domain of interest. As a result, we obtained a set of concepts as shown in Fig. 1.

Hierarchy Building. Once the concepts were defined, we created a hierarchy by identifying "is$a$ " and "part-of" relations. The concepts of higher level selected for the main ontology appear in the primitive concept hierarchy presented in figure 1 . We developed middle-out hierarchy approach for the lesson scenario and a top-down approach for the optic domain ontology. As a result, the hierarchy of the main ontology, that we call the Core ontology, has four levels. The optic domain ontology in our case, based on an official secondary school curriculum can be seen in Figure 1. Under the Optics domain concept, we have two sub-concepts, "Nature of Light" and "Optical Devices". Further in the hierarchy, the "Focal Length" concept is represented. The lesson scenario hierarchy based on "is- $a$ " and "part-of" relations, highlights "things that exist" in the instructional world and that are needed in our scenario. The "is- $a$ " hierarchy, which in top-down reading goes from the more abstract or generic to the more concrete or specific concepts, is represented in Figure 1 under two forms: a tree hierarchy on the left window and a graphical class representation on the right window. In the right window, another relation is represented: the "part-of" relation (or " $p / o$ " on the figure 2) between a concept and its components or "part-of" concepts. The "part-of" concepts of a concept co-exist in a given context, to provide particular semantics about that wholeness concept. In other words, all components co-existing in a "part-of" relation are needed in order to define wholeness concepts on which they depend. Then, 
when a wholeness concept instance is created, all its part-of concept instances are automatically generated. In our "activity sequencing” case, "part-of" (before, after, teaching, learning) relations are used to make clear that lesson scenario could be preceded or followed by other lessons and that teaching/learning activities co-exist in the same context to form a lesson scenario. In this way, we express the whole concept with its necessary and sufficient conditions of existence.

Relation setting. Most of the concepts defined need a set of properties and role relations to explicit the context in which they should be understood by agents. In that sense, the "attribute-of" relation was used as a property slot and the "part-of" relation as a role slot, as suggested by Kozaki [19].

Other relations can be created between concepts. The "participate-in" relation (or $p / i$ in the editor), is similar to the "part-of" relation, but is not included in the relational concept. This step allows us to describe connections between these concepts. For example, one stake of the ontology was to express a dynamic scenario showing a sequence of teaching/learning activities. To model these, we used a "before-after" relation which allowed expression of which activities happened before the current activity and which one happened after.

Figure 1 shows the Core Ontology that resulted from this development.

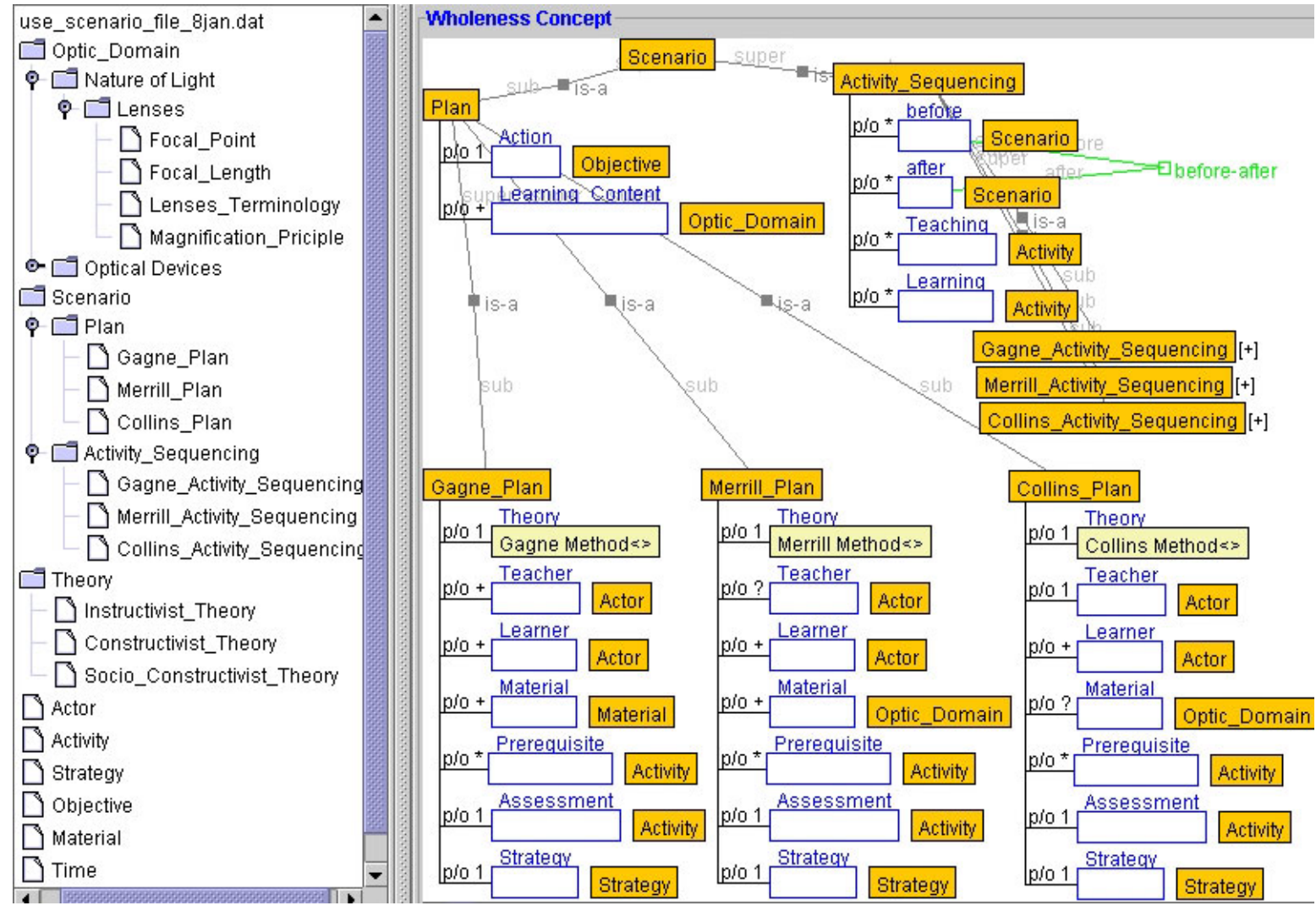

Figure 1. Core Ontology

Create instances (models). The models were built by instantiating the ontology concepts, then by connecting the instances to each other. The consistency checking of the model is done using the axioms defined in the ontology. The model is then ready to be used by others agents (human, software or both).

Three models have been built that rely on the main ontology, and relate to the Use Cases. These models of scenarios focus on the teaching/learning interaction based on each respective Instructional Theory. Figure 2 presents the model for the Gagné-Briggs theory. 


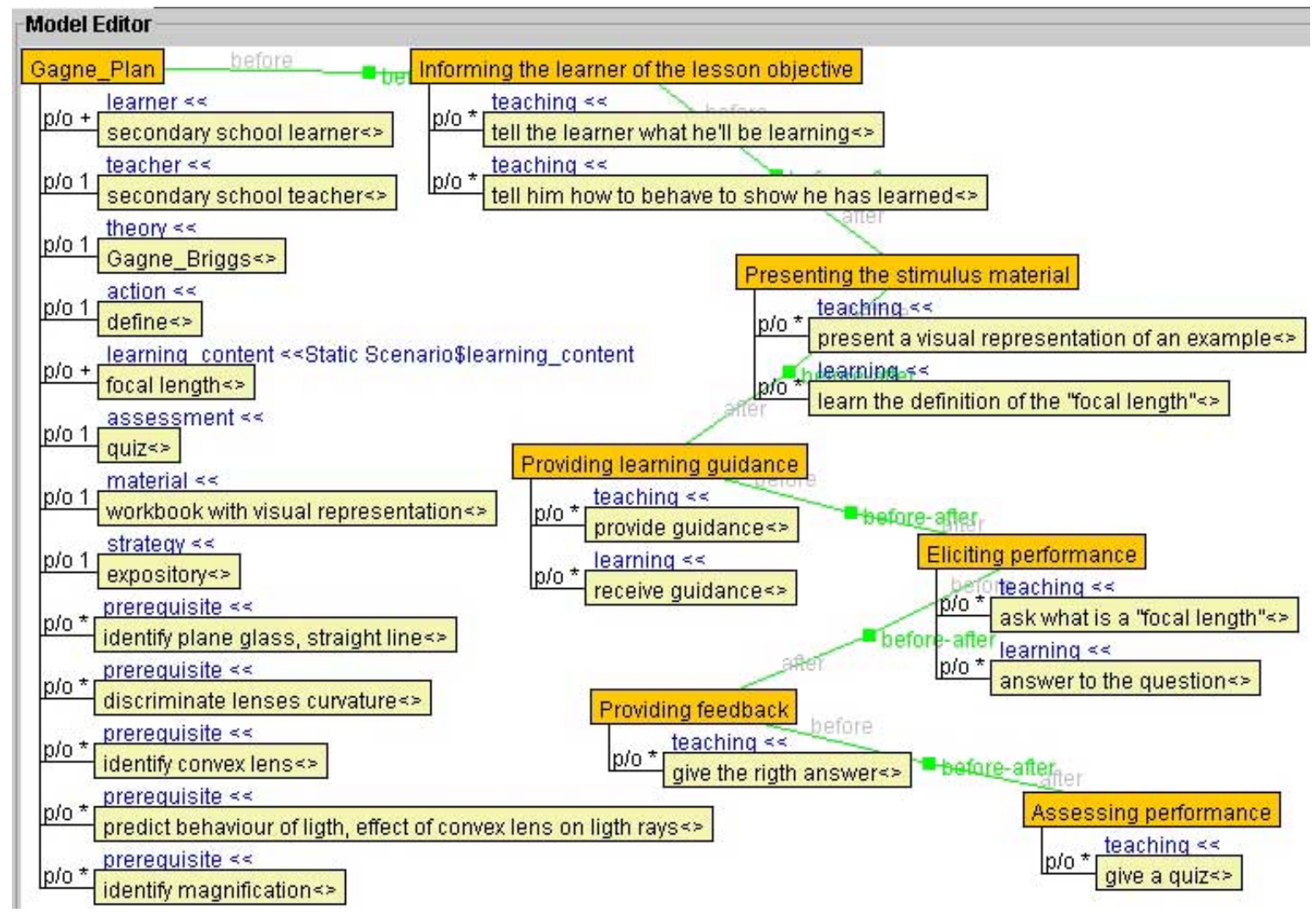

Figure 2. Model of Gagné-Briggs Theory

Six out of Gagné's nine events of instruction, which are needed to achieve the lesson scenario, are presented in Figure 2. The activities involved in the achievement of the lesson objective, are represented according to "Remember-Generality-Concept" from Merrill's performance/content matrix. In the same way, six of Collins's ten techniques of instruction, which are needed to achieve the lesson scenario according to this Theory, are represented in their event order. The most interesting part of these three models is that they explicitly show the role of each participant during the activities based on each theory.

\section{Conclusion}

As a conclusion, ontological engineering allowed for unifying the commonalities as well as specifying the variations in linking theories to concrete instructional strategies. Obviously, ontologies cannot go beyond the power of the theories themselves, and one should not expect from ontological engineering of theoretical knowledge more than what can be expected from the theories themselves.

This paper illustrates the idea that an Ontology-based ITS Authoring Environment can enrich the authoring process as well curriculum planning. One example is provided of how a theory-aware authoring environment allows for principled design, provides explicit justification for selection, may stimulate reflection among authors, and may pave the way to an integrated knowledge base of instructional theories. A theory-aware Authoring Environment also allows for principled design when it comes to assembling, aggregating and integrating learning objects by applying principles from theories. Further work in this direction will lead us to develop the system's functionalities, to implement them in an ITS authoring environment, and to conduct empirical evaluation. 


\section{References}

[1] Mizoguchi R. and Bourdeau J., "Using Ontological Engineering to Overcome Common AI-ED Problems," International Journal of Artificial Intelligence and Education, vol. vol.11, pp. 107-121, 2000.

[2] Mizoguchi R. and Bourdeau J. , "Theory-Aware Authoring Environment : Ontological Engineering Approach," presented at Proc. of the ICCE Workshop on Concepts and Ontologies in Web-based Educational Systems, Technische Universiteit Eindhoven, 2002.

[3] Mizoguchi R. and Sinitsa K., "Architectures and Methods for Designing Cost-Effective and Reusable ITSs," presented at Proc. ITS'96, Montreal, 1996.

[4] Chen W., Hayashi Y., Kin L., Ikeda M., and Mizoguchi R., "Ontological Issues in an Intelligent Authoring Tool," presented at Proc. of ICCE'98, 1998.

[5] Mizoguchi R., Kozaki K., Sano T., and Kitamura Y., "Construction and Deployment of a Plant Ontology," The 12th International Conference, EKAW2000,, pp. pp.113-128, 2000.

[6] Mizoguchi R., "Ontology-based systematization of functional knowledge," presented at Proc. of TMCE2002:Tools and methods of competitive engineering, Wuhan, P. R. China, 2002.

[7] Rubin D. L., Shafa F., Olivier D. E., Hewett M., and Altman R. B., "Representing genetic sequence data for pharmacogenomics: an evolutionary approach using ontological and relational models," vol. 18, pp. 207-215, 2002.

[8] Bourdeau J. and Mizoguchi R., "Collaborative Ontological Engineering of Instructional Design Knowledge for an ITS Authoring Environment," in Intelligent Tutoring Systems, Cerri S., Gouardères G., and Paraguaçu F., Eds.: Springer, Heidelberg, 2002, pp. 399-409.

[9] Murray T., "Authoring intelligent tutoring systems: an analysis of the state of the art," IJAIED, vol. 10, pp. 98129, 1999.

[10] Kay J. and Holden S., "Automatic Extraction fo Ontologies from Teaching Document Metadata," presented at Proc. of the ICCE Workshop on Concepts and Ontologies in Web-based Educational Systems, Technische Universiteit Eindhoven, 2002.

[11] Paquette G. and Rosca I., "Organic Aggregation of Knowledge Objects in Educational Systems," Canadian Journal of Learning and Technology, vol. vol. 28, pp. 11-26, 2002.

[12] Aroyo L. and Dicheva D., "Authoring Framework for Concept-based Web Information Systems," presented at Proc. of the ICCE Workshop on Concepts and Ontologies in Web-based Educational Systems., Technische Universiteit Eindhoven, 2002.

[13] Nkambou R., Frasson C., and Gauthier G., "Cream-Tools: an authoring environment for knowledge engineering in intelligent tutoring systems," in Authoring Tools for Advanced Technology Learning Environments : Toward cost-effective adaptative, interactive, and intelligent educational software, B. S. a. A. S. Murray T., Ed.: Kluwer Academic Publishers, 2002.

[14] Reigeluth C. M., "Instructional theories in action: lessons illustrating, selected theories and models," LEA, 1993.

[15] Mizoguchi R., "A Step Towards Ontological Engineering," presented at 12th National Conference on AI of JSAI, 1998.

[16] Gruninger M. and Fox M.S., "Methodology for the Design and Evaluation of Ontologies.," presented at Proceedings of the Workshop on Basic Ontological Issues in Knowledge Sharing, IJCAI-95, Montreal, 1995.

[17] Davis R., Shrobe H., and Szolovits P., "What Is a Knowledge Representation?," AI Magazine, 1993.

[18] Noy N. F. and McGuinness D. L., "Ontology Development 101: A Guide to Creating Your First Ontology," 2000.

[19] Kozaki K., Kitamura Y., Ikeda M., and Mizoguchi, R., "Hozo: An Environment for Building/Using Ontologies Based on a Fundamental Consideration of "Role" and "Relationship". Proc. of the 13th International Conference Knowledge Engineering and Knowledge Management (EKAW2002), pp.213-218, Siguenza, Spain, October 1-4, 2002. 